\title{
The Tele-Underwriting Process And Protective Value Study
}

Han B. Kang, Illinois State University, USA

\begin{abstract}
A primary objective of the study is to discuss the process of tele-underwriting and its associated benefits and costs. Tele-interviewing or tele-underwriting offers insurers an effective alternative to more traditional methds by complementing physician reports and other medical status reports, thus reducing underwriting expenses. The telel-underwriting system involves a call center that gathers medical information through a phone interview with applicants, reducing errors associated with paper handlings. Then, a detailed statistically analysis can be performed for determining what type(s) of paramedic exams are needed. It can be an efficient system as long as the benefit of the tele-underwriting services exceeds its cost. Large insurers can have an in-house call center or small firms can use an outsourcing services of tele-underwriting. Nine out of ten customers are satisfied with the tele-underwriting services. However, each firm must consider the costs associated with the tele-underwriting system. Therefore, a cost/benefit or protective value study is essential for the success of the program.
\end{abstract}

Keywords: underwriting, protective study, insurance

\section{INTRODUCTION}

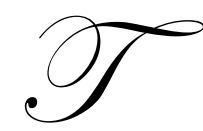

he objective of life underwriting is to evaluate each applicant's mortality risk and decide whether an insurer accepts or rejects an application. Furthermore, the underwriting process is set to make appropriate premiums rates based on the applicant's risk. Mortality factors for the life/health insurance include age, sex, physical condition, medical history, family medical history, occupation, hazardous avocations, financial information, etc. A life underwrite has a wide variety of tools available to help assess the mortality risk of application and can choose appropriate tools (Griffin, 2004).

The choice of underwriting tools depends upon many factors. First, an underwriter must consider the cost of obtaining and handling the information. Life insurance companies do not want to spend high underwriting expenses for a low risk application. Also, it is unnecessary to pay high underwriting costs on the insurance application of a small insurance amount. Second, an underwriter must collect the information that is relevant of mortality significance. Third, an underwriter must consider the availability of data and the time spent for obtaining mortality information. Long delays in the underwriting process can result some cancellations of insurance applications. Finally, an underwriter should adopt a policy or a guideline of underwriting: lenient, moderate and strict. A lenient underwriting policy can save underwriting expenses, but it may result in a higher claim costs in future. On the other hand, a strict underwriting policy can cost higher underwriting expenses now, but it can reduce a moral hazard problem and insurance fraud later that lead to lower claim costs. In other words, the cost and benefit analysis is essential for underwriting practices.

\section{LIFE INSURANCE UNDERWRITING PROCESS}

The primary sources of risk selection information are questions on application, inquiries/inspections, APS (Attending Physician's Statement), and medical examinations. This study addresses the issue of how to obtain the medical data/history of applicants and their families in a fast and cost-saving manner. The main objective of the study is to examine how to achieve an efficient underwriting at a minimum cost. It is a critical issue facing all insurers today, considering the fact that they must cut costs to survive and compete with other insurers. 
Insurance application is the most single important source of mortality information. It includes medically related questions, hazardous sports activity, aviation, occupation, motor vehicle record, use of tobacco, history of treatment for alcohol or drug abuse, etc. Also, the application can include authorization of release medical information, pre-notification forms for the Medical Information Bureau (MIB), and conditional receipt for advance premiums paid. The Medical Information Bureau is a non-profit trade association of life insurance companies that provides its members with necessary medical information on applicants. The MIB has a large data base of confidential information and releases it only to member companies who have a signed written authorization permitting the company to contact MIB (Bergstrom and Freitas, 2000).

Next step of underwriting involves medical exams. There are three types of medical exams used for life insurance underwriting: full medical exam, paramedical exam and mini-paramedical exam. The full medical exam can be applied to high risk applicants or policies with a large insurance amount, and it should be completed by a physician. The paramedical exam includes medical history questions, measuring of height, weight, blood pressure, and other tests such as blood, urine, HIV, cocaine, tobacco, etc. The mini-paramedical exam consists of a simple procedure of the weight, blood pressure and pulse taken by a technician. Most insurers require the mini-paramedical exam for low risk applicants or policies with a small amount of insurance (Bergstrom and Schmit, 2000).

Agent's report is another important source of underwriting. It includes non-medical and financial information on the applicant that the agent provides based on the agent's knowledge of the applicant. The agent can report on the purpose of the insurance, details of other insurance in force, income and net worth on the proposed insured, how long the agent has known the application, etc. Furthermore, as mentioned before, the underwriting process requires inspection reports, questionnaires, motor vehicle report, financial statements, attending physician's statement and relevant medical exams such as urinalysis, blood tests, oral fluid test, electrocardiogram, chest X-ray, pulmonary function test, etc. (Bergstrom and Schmit, 2000).

\section{TELE-UNDERWRITING PROCESS}

As mentioned earlier, a key issue for underwriters today is to choose appropriate underwriting tools and obtain necessary information at low costs. A traditional practice of obtaining the medical information on applicants involves filling out page after page of questions. It is a time-consuming task and takes a lot of agents' time dealing with applicants. It is not efficient in a sense that papers can be misfiled, misplaced, or lost. Therefore, our insurance industry began to realize an importance of tele-underwriting. Use of tele-underwriting is one way of saving time and reducing costs. Today's insurance market is highly competitive. Insurers must find various ways to simplify and improve underwriting, lowering underwriting expenses. An efficient underwriting system can free up time for the agent so that the agent can spend more time on sales and client satisfaction.

Tele-underwriting requires an applicant to fill out a short one-page information form with agents. Then, an underwriter at a home office or a call center gathers medical risk information through a phone interview with prospective applicants. Trained callers can instantaneously input the medical information on a PC while conducting a phone interview, saving time and reducing the errors associated with paper works. Then, a software of an expert system can statistically analyze the input data of the medical information and determine what types of medical exams are needed for each case. Insurers can have an in-house call center or hire an outsourcing firm of teleunderwriting (Testa, 2001).

The first step of tele-underwriting involves a short application form that an applicant fills out and signs. It contains basic client demographics and very limited medical information. This short information form can be mailed or faxed to an underwriting department of home office. The agent and applicant do not have spend a lot of time on filling out a complicated long application at this early stage of processing an application, saving time for the agent. The agent can concentrate on sales and marketing efforts rather than spending a lot of time with the applicant on the underwriting. The simplified form contains data on the basic features of the sale and some statements of applicant understanding. Also, it can include some authorizations that are required to obtain more detailed information later and issue life policies (Sashihara, 1997). 
The second step of tele-underwriting involves tele-interviewing at a call center. Medically qualified personnel and trained nurses make phone calls to the applicant and conduct phone interviews. Tele-interviewers also have knowledge on customer service and computer/data entry skills. The centralized system is more efficient and time-saving system because sales people do not have to handle medically related issues with applicants. Callers at the call center do not have to be located at home office. The call center can be located at a remote area in a suburban area where office rental rates and callers' living expenses are low. In recent years an increasing number of insurance companies use remote workers at call centers for the gathering of underwriting information. Some companies have in-house call center whereas other firms outsource the tel-underwriting business (Gilmore, 2002).

A successful tel-underwriting involves a good training program for callers. Only qualified workers are supposed to conduct phone interviews and ask medical questions. It includes medical terminology training, classroom training on common impairments, communication skills, and problems solving techniques. Callers must have knowledge on insurance basics, underwriting, case management, medical/paramedical exams and regulatory/privacy affairs. Furthermore, callers must be trained on computer and software technologies since the tele-underwriting involves a paper-less system. A drill-down expert system is a key element of the computerized tele-underwriting system. It stores all case information regarding applicant and policy, automatically provides scripts pertaining to the policy and any other information provided by the applicant, uses drill-down scripts to handle additional related questions, analyzes all the answers obtained by phone interview, and determines what additional steps or medical examinations are required.

The next step of tele-underwriting involves an electronic evaluation of all the obtained information through tele-underwriting. An underwriter at a home office receives all the information required for evaluating applications and can accept or reject the insurance application. The underwriter can order medical examinations if they are deemed necessary. We have to understand that there is a limit on how much a machine or software can do. The fact is that the underwriting requires a human judgment. Use of electronic system helps us to save time and reduce errors, avoiding the collating, copying and manual routing of papers. The final step of tele-underwriting involves sending a confirmation letter and a policy to the applicant once the case is completed (Dolan, 2001).

\section{TELE-UNDERWRITING ADVANTAGES}

The Tele-underwriting system can benefit all parties involved in many ways: applicant, sales agent, underwriter, insurers and reinsurers. It can result applicants' satisfaction through a greater efficiency, privacy and a high level of professionalism. The applicant benefit includes a shorter process time, fewer signatures and required forms to complete, no need to provide private medical history to sales agent, faster customer service and status updates with electronic case folder, and eliminates need for additional contact to get incomplete information. Sales agents can save time and receive commission faster due to a more efficient system of tele-underwriting. The other benefits of the sales agent includes increased placement ratio due to higher customer satisfaction and lower applicant drop-out rate, no need to ask potentially embarrassing questions of applicant, and frequent updates of the current status of underwriting (George, 2004).

Tele-underwriting also can benefit underwriters at a home office. They can gather more accurate, in-depth information from applicant via scripted calls, manage risk and mortality experience more cost-effectively with a greater precision, reduce errors and missing information from applications, and achieve high efficient gains with the automated administrative function. Recorded calls can be used for reviews, future trainings and consumer challenges. Furthermore, the tele-underwriting can reduce the need for Attending Physician's Statements (APS), reducing costs.

Also, a well-designed tele-underwriting system can benefit the insurer and reinsurer. The insurer can achieve improved placement ratios and resulting higher revenues. Better standardization and consistency in data can also help improve standing with reinsurers. Other benefits to the insurer include a greater efficiency through a paperless system, an enhancement of marketability of products with improved focus on customer service, and recorded interviews that can be used for future claim settlements. The reinsurer can benefit from the tele-underwriting system through the accuracy of gathered information. Audits can be standardized because of the consistency of information gathered. Also, audits can include a review of recorded interviews. 
The bottom line is that the efficient system of the applicant/underwriter interaction through teleunderwriting saves time. Normally, a policy can be issued within two weeks after an initial application is received. We believe that there is a strong correlation between delays in policy delivery and cancellations. An industry research indicates that the 10 days' delay of issuing policies can reduce an insurer's revenue by $1.5 \%$ while the 20 days' delay can cut the revenue by 3\%. Tele-underwriting directs each element of the sales process to qualified specialists at a call center who handle the data collection and analysis in a highly efficient manner. It is an efficient and low-cost marketing system for all parties involved (George, 2003).

\section{THE PROTECTIVE VALUE OF TELE-UNDERWRITING}

As mentioned earlier, an effective tele-underwriting can reduce underwriting expenses, but each firm must consider the costs associated with tele-underwriting. The tele-underwriting requires much expenditures such as hiring and training callers, advanced software system, setting up sophisticated telephone system, additional office spaces, etc.

The savings for a particular policy can depend upon the age and gender of the applicant, the face amount of the policy, and the type of policy such as whole life or term. The savings of tele-underwriting can be spread out over time, so we should consider a present value of savings and compare it to the total cost of the tele-underwriting system. In a cost/benefit analysis, we can calculate a cost/benefit ratio. Over a period of time, a cost/benefit ratio would be the expected costs of a specific underwriting procedure divided by the expected amount of the resulting "mortality savings." In other words, the protective value is measured by a ratio of present value of expected savings generated by tele-underwriting minus the cost of tele-underwriting. One can say that a "protective value" exists when savings exceeds costs after we take care of the time value of money. It can be measured by comparing the loss ratio of a traditional system to the loss ratio of tele-underwriting.

Let's consider a simple hypothetical example. Suppose that over a year we expect to test 1000 applicants for impairment using a blood test. Assume that each blood test costs $\$ 30$. The total expected cost would them be $\$ 30,000$. Also assume that we expect $0.5 \%$ of the tests to be positive. It means that 5 tests would return a positive result. Suppose that, based on an expected distribution of insured/policy characteristics, we find that the 5 policies will return a total mortality savings of $\$ 60,000$. The cost/benefit ratio would then be 0.5 , meaning that each dollar spent on impairment $\mathrm{x}$ investigations results in $\$ 2.0$ of savings in mortality risk.

Richard Bergstrom and Stephen Freitas jointly performed a protective study of the MIB inquiry service. The Medical Information Bureau (MIB) provides medical information to its members and charges fees. Their study indicated the present value of savings of the MIB services was $\$ 0.18$ per thousand applied for life insurance, which is a savings/cost ratio of 46:1. The comparable ratio for health insurance was 49:1. It indicates that additional costs to obtain necessary medical information can be justified. The Milliman company conducted another protective value study on the MIB checking services. They examined 894 MIB checking cases of health insurance and found a significant improvement on loss ratio by six percentage points. The study estimated $\$ 43$ to $\$ 51$ savings on every dollar paid for the MIB services.

\section{SUMMARY AND CONCLUSION}

Tele-interviewing and tele-underwriting offer insurers an effective alternative to more traditional options by complementing physician reports and other medical status reports, thus reducing underwriting expenses. The outcome of tele-interview can help make the subsequent choice of medical tests more relevant. The electronic system of tele-underwriting provides a way of collecting accurate and complete medical and financial data within a short time frame so that underwriting decisions can be made without delay. A call center offers trained professionals and nurses who have medical knowledge and proper trainings on client satisfaction. Tele-underwriting uses a drill down questionnaire to investigate disclosures as effectively as possible. All calls are recorded in case of query and for further review and training. The paper-less system saves time and reduces cancellation of policies. Policies can be issued in a timely manner, increasing revenue. However, each firm must consider the costs associated with the tele-underwriting system. Therefore, a cost/benefit or protective study is essential for the success of the program. 
Also, it should be emphasized that we need to improve the tele-underwriting system to make it more cost-efficient by utilizing advanced technologies.

\section{AUTHOR INFORMATION}

Han Bin Kang is a professor at the Department of Finance, Insurance and Law, Illinois State University. He joined the University in 1983 and taught corporate finance, insurance and real estate courses. Dr. Kang's insurance research includes insurance fraud, service quality in automobile insurance, redlining, distribution systems, premiums comparisons, economies of scale, and underwriting profit cycles. He has published articles in the Journal of Banking and Finance, the Journal of Real Estate Research, American Real Estate and Urban Economics Association Journal, Southern Business Review, Journal of Business and Behavioral Science, Midwest Review of Finance and Insurance, etc.

\section{REFERENCES}

1. Bergstrom, Richard and Deborah Schmit, Life Insurance Underwriting Tools: An Overview of the Purpose, Costs, and Benefits of Current Risk selection Tools, A Research Report from Milliman \& Robertson, Inc. pp. 1 - 21, July, 2000.

2. Bergstrom, Richard and Stephen A. Freitas, A Protective Value Study of the MIB Inquiry Service, www.mib.com.

3. Dolan, Vera F. On the Risk Special Report: Highlights of the 2000 IHOU, On The Risk, Vol. 17, No. 1 (2001), pp. $20-30$.

4. Jon, Shreve, The Impact of the MIB Checking Service on Health Insurance Underwriting, Milliman Protective Value Study, Milliman, Inc.

5. George, Hank, On the Risk Special report: Highlights of LOMA's 2003 International Underwriting Congress in Singapore, On The Risk, Vol. 19, No. 4 (2003), pp. $69-75$.

6. George, Hank, Teleunderwriting 2004: Where Are We?, On The Risk, Vol. 20, No. 3 (2004), pp. 22 - 28.

7. Gilmore Debi J. Myths and Magic: Remote Working, Call Centers and Their Role in Underwriting, On The Risk, Vol. 18, No. 1 (2002), pp. 54 - 59.

8. $\quad$ Griffin, Kenneth H. Underwriting Decision Model, On The Risk, Vol. 20, No. 4 (2004), pp. 8 - 20.

9. $\quad$ Life Insuance, Korea Life Insurance Association, Vol. 335, January, 2007, p. 94.

10. Sashihara Steve, The New Client Acquisition Process: Tele-Underwriting Is Only The Beginning, On The Risk, Vol. 13, No. 2 (1997), pp. 97 - 102.

11. Testa, Ernest A. Teleunderwriting: Is It the Right Solution for You? On The Risk, Vol. 17, No. 2 (2001), pp. $40-46$. 
NOTES 